\title{
The management of low-stage non-seminomatous germ cell tumors
}

\author{
Louise Lim, Thomas Powles \\ Department of Medical Oncology, Barts Cancer Institute, QMUL, Experimantal Cancer Med St. \\ Bartholomew's Hospital London, UK
}

\begin{abstract}
The prognosis of patients with stage I non-seminomatous germ cell tumors is in general very good. However, a large number of patients relapse with metastatic disease after orchidectomy Therefore, adjuvant treatment, in the form of either chemotherapy or retroperitoneal dissection is recommended, although active surveillance has been found to be as good a way of treating these patients with overall excellent results.
\end{abstract}

\section{Introduction}

There is an increasing number of patients presenting with stage I germ cell tumors ${ }^{1}$ which may reflect the overall increase in awareness of this type of disease in young men. The prognosis for both stage 1 seminomas and non-seminomas is excellent after surgery regardless of the subsequent management. In a recent study with 740 stage I nonseminomatous germ cell tumors (NSGCT) patients, results showed that there were no NSGCT related deaths, ${ }^{2}$ underlying the challenging aspect of carrying out prospective randomized studies in NSGCT, as the control arm has a survival of nearly $100 \%$. Adjuvant chemotherapy, retroperitoneal lymph node dissection (RPLND) and active surveillance are all potential treatment options after orchidectomy. These have all become accepted standards of care, the evidence for which is predominantly based on single arm descriptive studies (Tables 1-3). . $^{\text {- }}$ 12 The lack of randomized data favoring one treatment over another has resulted in different treatment pathways between institutions and countries. Europe leans towards surveillance and adjuvant chemotherapy and North America towards surveillance or RPLND. ${ }^{13}$ In view of the

Correspondence: Louise Lim and Thomas Powles, Barts and the London NHS Trust, Charterhouse Square, London, UK.

Tel.+44.0207.601 8522 - Fax: +44.0207.7510571.

E-mail: thomas.polwes@bartsandthelondon.nhs.uk

Key words: non-seminomatous germ cell cancer, surveillance, adjuvant therapy.

Received for publication: 27 April 2012.

Revision received: 30 July 2012 .

Accepted for publication: 1 August 2012.

This work is licensed under a Creative Commons Attribution NonCommercial 3.0 License (CC BY-NC 3.0).

(C) Copyright L. Lim and T. Powles, 2012

Licensee PAGEPress, Italy

Oncology Reviews 2012; 6:e19

doi:10.4081/oncol.2012.e19 fact that the majority of patients with stage 1 NSGCTs do not relapse after orchidectomy, blanket adjuvant treatment in these individuals is thought to be counterproductive and, indeed, cause more toxicity. ${ }^{14}$ Therefore, a stratified approach to treatment, based on the identification of risk factors associated with relapse, has been formulated. ${ }^{15}$

\section{Stage 1 disease}

Clinical stage 1 disease is defined as no evidence of disease on a staging CT with normal serum tumor markers: alpha fetoprotein, human chorionic gonadotrophin, and lactate dehydronronase. Patients who have persistently raised makers post orchiectomy are considered to have extragonal disease and chemotherapy is recommended. ${ }^{16}$ The role of RPLND in this setting is unclear as relapses outside of the surgical field have been frequent. The retroperitoneal lymph nodes are the commonest sites (>70\%) of metastatic spread in $\mathrm{NSGCTs}^{17}$ with a cut off of more than $1 \mathrm{~cm}$ being considered abnormal. However, borderline lymph nodes of $8-10 \mathrm{~mm}$ may be worthy of more frequent investigation or intervention. ${ }^{18}$ Unlike RPLND, CT scanning understates retroperitoneal disease in 25-30\% of patients. ${ }^{19}$ However, RPLND is associated with morbidity and is thus not considered routine procedure to complete staging. The role of fluorodeoxyglucose-positron emission computed tomography (FDG-PET/CT) is still undefined and cannot be recommended in the routine staging of this disease. ${ }^{20}$ Histological features which predispose to relapse include tumor invasion of testicular veins, lymphatic invasion by the tumor, absence of yolk sac elements, and the presence of embryonal cell carcinoma within the cancer. The absence of any of these features resulted in a $100 \%$ relapse free survival over three years while the presence of 3 or 4 of these resulted in a $58 \%$ relapse rate over this same period. ${ }^{21}$ These data were successfully externally validated in a larger cohort. ${ }^{14}$ The presence of venous and lymphatic invasion is now taken to represent one prognostic feature. Along with the presence of embyronal carcino$\mathrm{ma}$, these have become the most important prognostic factors. ${ }^{10} \mathrm{~A}$ recent retrospective analysis of 23 publications from between 1979 and 2001 investigated prognostic factors in over 2500 patients with stage 1 NSCGT. ${ }^{22}$ Lymphovascular invasion remained the most significant prognostic factor (odds ratio 5.2; 95\% CI: 4.0-6.8). Other factors, such as embryonal carcinoma in the primary tumor (OR 2.9; 95\% CI: 2.0-4.4) and a high pathological stage of the tumor (OR 2.6; 95\% CI: 1.8-3.8), were also of significance. Overall, despite conflicting data with other markers, vascular invasion is the only prognostic factor which is consistently significant in this area. Markers such as MIB-1, p53, bcl-2, cathepsin D and E-cadherin have been investigated with mixed results. ${ }^{10}$

\section{Retroperitonal lymph node dissection for stage I non-seminomatous germ cell tumors}

In NSGCT, the landing zones within the retroperitoneum are the most commonly affected sites. RPLND can be used to accurately differentiate stage I and II disease and can also significantly reduce the 
probability of systemic relapse. Indeed, relapse within the retroperitoneal field post RPLND occurs in less than $1 \%$ of patients and overall survival is in the region of $99 \%$ at five years. ${ }^{5,6}$ This approach appears to be safe and successful with relatively few long-term side effects, retrograde ejaculation being the notable exception. RPLND also has the potential advantage of removing any chemoresistant mature teratoma, which can be present in $30 \%$ of patients with stage II disease and which can undergo malignant transformation at any point. ${ }^{23}$ The absence of mature teratoma in the primary tumor does not correlate with absence in the retroperitoneal lymph nodes, making it difficult to predict which patients may benefit from surgery. ${ }^{24}$

There are relatively few documented long-term side effects with RPLND. Series published from Indiana University and the Cleveland Clinic reported no perioperative deaths or permanent disability. Major complications were reported in only $2-3 \%$ of patients. ${ }^{25}$ The most significant long-term side effect with RPLND is retrograde ejaculation. It is, however, thought that these excellent results are in part due to the number of procedures carried out and the high levels of surgical expertise available and, therefore, may not be reproducible in the community setting. ${ }^{26}$ The main disadvantage to RPLND is that, in $5 \%$ of patients, relapse can occur outside the retroperitoneum. ${ }^{26}$

A randomized prospective study from the German group compared one cycle of bleomycin+etoposide+cisplatin (BEP) with RPLND ${ }^{26}$ in this setting. Sixty-one centers participated throughout Germany. The results showed that after a median follow up of over four years, none of the patients had died of GCT. However, 15 patients had recurrence (2 in the chemotherapy arm vs 13 in the RPLND arm; $\mathrm{P}<0.005)$. Thirteen of the 15 recurrences in the RPLND arm had been observed within 17 months of therapy; 5 (3\%) of these relapses occurred after RPLND. However, there may be specific issues to consider. In particular, it was thought that relatively inexperienced institutions performing a small number of operations may be responsible for these findings. Also, the fact that ipsilateral RPLND was performed may explain the relatively high relapse rate with surgery (3\%). ${ }^{5,6}$ This was then compared to one cycle of BEP chemotherapy which is not considered the standard of care. ${ }^{15}$ The conclusion of this study was that RPLND may be best performed in specialist centers with the appropriate surgical expertise. ${ }^{27}$

Overall, RPLND is becoming less widely used, especially in Europe. This may in part be due to the technical challenges required.

\section{Surveillance for stage I non-seminomatous germ cell tumors}

Surveillance after orchiectomy is an attractive option, particularly in the absence of high-risk features where the chances of relapse are under $20 \%{ }^{10}$ (Table 2 ). It is also a potential option in the high-risk setting, as only approximately $50 \%$ of these patients relapse, resulting in the remainder being unnecessarily over-treated. In view of the good results in overall survival seen with surveillance alone (98-100\%), some institutions follow a surveillance program for all patients with stage I NSGCT. ${ }^{10}$ The other advantage of using surveillance as a treatment option is that when relapses do occur, they do so in predictable anatomical locations. Relapse invariably occurs within two years of orchidectomy with an associated rise in tumor markers in one-third of patients with metastatic disease, hence resulting in few late relapses. ${ }^{4}$

Cross-sectional imaging with CT has been shown to detect approximately $48-53 \%$ of relapses while raised serum tumor makers detect 29 $39 \% .^{2}$ Follow up of these patients thus tends to focus on regular crosssectional imaging with regular tumor marker measurements over the first two years. Subsequent imaging between years 2-5 varies depending on the treatment center, ${ }^{13}$ and serum tumor makers are also measured on a regular basis during this period. The introduction of prognostic factors, such as vascular invasion and adjuvant therapy, reducing the risk of relapse, complicates this issue further. The radiation exposure of CT is not without risks and the follow up with tumor markers generates anxiety to the patient.

Guidance on imaging scheduling varies depending on the individual institution. The most recent recommendations from the German Collaborative Group covers this issue in detail. ${ }^{28}$ These guidelines identify a balance between the potential risks associated with radiation exposure and the need to identify relapse. They have separated the non-seminomatous patients into 3 groups: low-risk surveillance, high-

Table 1. Summary of studies investigating retroperitoneal lymph node dissection in stage I non-seminomatous germ cell tumors.

\begin{tabular}{|c|c|c|c|c|}
\hline Study & $\begin{array}{c}\text { No. } \\
\text { patients }\end{array}$ & $\begin{array}{l}\text { Relapse rate } \\
\text { for pathology } \\
\text { stage I* }\end{array}$ & $\begin{array}{c}\text { Relapse rate } \\
\text { for pathology } \\
\text { tage II* }\end{array}$ & $\begin{array}{l}\text { Overall } \\
\text { survival }\end{array}$ \\
\hline $\begin{array}{l}\text { Albers }^{3} \\
2003\end{array}$ & 182 & $18 \%$ & $25 \%$ & $\mathrm{NA}$ \\
\hline $\begin{array}{l}\text { Nicolai }{ }^{4} \\
2004\end{array}$ & 322 & NA & NA & $99 \%$ \\
\hline $\begin{array}{l}\text { Stephenson }{ }^{5,6} \\
2005\end{array}$ & 309 & $7 \%$ & $34 \%$ & $99 \%$ \\
\hline
\end{tabular}

Table 2. Surveillance for patients with stage I non-seminomatous germ cell tumors.

\begin{tabular}{|c|c|c|c|c|}
\hline Study & $\begin{array}{c}\text { No. } \\
\text { patients }\end{array}$ & $\begin{array}{c}\text { Follow up } \\
\text { (years) }\end{array}$ & $\begin{array}{c}\text { Relapse } \\
\text { rate }\end{array}$ & $\begin{array}{l}\text { Overall } \\
\text { survival* }\end{array}$ \\
\hline $\begin{array}{l}\text { Daugaard }{ }^{7} \\
2003\end{array}$ & 349 & 5 & $29 \%$ & $100 \%$ \\
\hline $\begin{array}{l}\text { Ernst }^{8} \\
2005\end{array}$ & 194 & 4.5 & $29 \%$ & $100 \%$ \\
\hline $\begin{array}{l}\text { Oliver }^{9} \\
2004\end{array}$ & 234 & 3.0 & $30 \%$ & $98 \%$ \\
\hline $\begin{array}{l}\text { Sturgeon }{ }^{10} \\
2010\end{array}$ & 371 & 6.3 & $28 \%$ & $99 \%$ \\
\hline
\end{tabular}

Table 3. Summary of studies investigating adjuvant chemotherapy in high risk stage I non-seminomatous germ cell tumors.

\begin{tabular}{lcccccc} 
Study & $\begin{array}{c}\text { No. } \\
\text { patients }\end{array}$ & $\begin{array}{c}\text { Chemotherapy } \\
\text { regimen }\end{array}$ & $\begin{array}{c}\text { No. } \\
\text { cycles }\end{array}$ & $\begin{array}{c}\text { Duration } \\
\text { of } \\
\text { follow up } \\
\text { (years) }\end{array}$ & $\begin{array}{c}\text { Relapses } \\
(\%)\end{array}$ & $\begin{array}{c}\text { Testis } \\
\text { cancer } \\
\text { deaths } \\
(\%)\end{array}$ \\
$\begin{array}{l}\text { Chevreaul } \\
2004\end{array}$ & 40 & BEP & 2 & 10 & $0 \%$ & $0 \%$ \\
$\begin{array}{l}\text { Oliver } \\
2004\end{array}$ & 28 & BEP & 2 & 3 & $4 \%$ & $4 \%$ \\
$\begin{array}{l}\text { Oliver } \\
2004\end{array}$ & 47 & BEP & 1 & 3 & $7 \%$ & $0 \%$ \\
$\begin{array}{l}\text { Dearnley } \\
2005\end{array}$ & 115 & BOP & 2 & 6 & $2 \%$ & $1 \%$ \\
\hline $\begin{array}{l}\text { Tandstad } \\
2009\end{array}$ & 157 & BEP & 1 & 5 & $3 \%$ & $0 \%$ \\
\hline
\end{tabular}

BEP, bleomycin+etoposide+cisplatin; BOP, bleomycin+vincristine+cisplatin. 
risk surveillance, and high-risk adjuvant chemotherapy. These practical guidelines also focus to some extent on ultrasound scanning of both the abdomen and testis.

They recommend that patients with low-risk disease on active surveillance should have check ups, have tumor markers tested, and have chest $\mathrm{X}$ rays every two months for the first two years. They then recommend less frequent check ups from 3 to 10 years. They recommend CT scanning of the abdomen at four months and one year only. They then adopt annual ultrasound scanning of the abdomen with chest $\mathrm{X}$ rays. This risk stratification approach reduces radiation exposure for these low-risk patients.

They recommend that the high-risk patients are seen more frequently (monthly) and have more frequent CT scans (3-monthly) in the first year. During the second year, they recommend a CT at 24 months. They use chest $\mathrm{X}$ rays and abdomen ultrasound at other time points. This more intensive regime reflects the higher risk of relapse in this subgroup. Subsequent follow up visits from years 3 to 10 are similar to those seen in the low-risk population. Recommendations for the final group (adjuvant therapy) are the least intensive, with 3-monthly appointments and testing for tumor markers for the first two years. Chest $\mathrm{X}$ rays and ultrasound scans were suggested at six and 18 months, with CT abdomen/chest $X$ rays at 12 and 24 months. Subsequent follow up from years 3 to 10 focuses on annual ultrasound scans and chest $\mathrm{X}$ rays. Details can be found in the published German Collaborative Group Guidelines. ${ }^{28}$ A prospective study compared 2 and 5 CT scans over the first two years of follow up after orchiectomy. ${ }^{26}$ The results showed that less frequent imaging did not increase the risk of relapse with more advanced disease. In view of this it seems wise to follow the guidance given in this study with fewer scans so that patients are exposed to less radiation. Finally, FDG-PET has been investigated as a follow-up procedure for patients with a low risk of relapse on surveillance. Sadly, the risk of relapse remains high even in the PET negative patients. ${ }^{29}$ However, the main concern with surveillance is the comparatively high risk of relapse compared to patients who undergo RPLND and adjuvant chemotherapy, especially in high-risk patients. Waiting until relapse occurs may also result in a significant proportion of patients requiring RPLND post chemotherapy, as many patients do not achieve a radiological complete remission with chemotherapy for stage II disease. ${ }^{30} \mathrm{~A}$ key issue regarding this approach is the need for good compliance during follow-up regimens. If this is considered an issue, adjuvant therapy is likely to be more attractive. Surveillance appears overall to be safe and very attractive, providing patients comply with follow-up appointments and cross-sectional imaging protocols. The lack of randomized data in this area should not discourage clinicians from pursuing this approach, especially in those patients with low-risk disease.

\section{Adjuvant chemotherapy for stage I non-seminoma- tous germ cell tumors}

The success of cisplatin-based combination chemotherapy in metastatic germ cell tumors has prompted the investigation of these drugs in the adjuvant setting in high-risk stage I NSGCT. ${ }^{15}$ Table 3 shows the different regimens that have been used. There is no clear pattern in the regimen and number of cycles of chemotherapy used; however, the current gold standard of treatment consisting of two cycles of adjuvant BEP chemotherapy was described by Cullen et al. ${ }^{15}$ In this MRC study, 116 high-risk patients ( $>50 \%$ chance of relapse) with stage I NSGCT were given two cycles of cisplatin $100 \mathrm{mg} / \mathrm{m}^{2}$, bleomycin $30 \mathrm{mg}$ weekly $\mathrm{x} 3$, and etoposide $120 \mathrm{mg} / \mathrm{m}^{2}$ x 3 (BEP). After four years of follow up, only 2 patients relapsed. There was minimal short-term toxicity; however, uncertainties remain over longer term toxicity. This is a particular concern regarding the development of secondary cancers and cardiovascular disease. ${ }^{31}$
Other studies have looked at trying to reduce the number of cycles of BEP from 2 to $1 .^{2}$ This has the theoretical benefit of reducing toxicity; however, there is no direct comparison in terms of efficacy between one and two cycles. It seems unlikely that simply reducing one cycle of treatment will have a major impact on long-term toxicity. ${ }^{31}$ The largest study to report results after one cycle of BEP presented findings comparable with two cycles of BEP. ${ }^{2}$ Once again, however, follow up was short and there is a lack of long-term follow-up data. With relapse free survival rates at around $95 \%$ for both regimens, a randomized study in this setting seems unrealistic as the number of patients required to prove non-inferiority would be huge. Many investigators in Europe have adopted one cycle as standard and at the most recent European review of this topic, one cycle was felt to be a standard treatment. There is an ongoing clinical tiral investigating one cycle of BEP in this setting to further validate these results (MRC 111 study).

Another study of interest investigated two cycles of cisplatin and bleomycin with vincristine instead of the etoposide (BOP).${ }^{12}$ Etoposide is thought to be an unfavorable agent in the adjuvant setting as it is associated with toxicity such as alopecia, myleosuppression and the development of leukemia. ${ }^{32}$ Indirect comparisons suggested the results for BOP were comparable with two cycles of BEP in terms of efficacy; however, high levels of neuropathy were seen with BOP and it was concluded that it had no advantage over BEP. There have been concerns that adjuvant therapy may only be delaying the time to relapse although this does not appear to be the case. ${ }^{33}$

Overall, these studies show cisplatin-based chemotherapy reduces the risk of relapse in the high-risk population from approximately $50 \%$ to less than $10 \%$. These results are attractive, but without accurate long-term follow-up data it is not possible to recommend chemotherapy as standard of care for all patients. This is particularly true given that chemotherapy can potentially increase the risk of cardiovascular disease, neurological toxicity, fertility problems, metabolic syndromes and secondary cancers. ${ }^{34}$

\section{Survivorship}

The introduction of chemotherapy heralded a revolution in the outcome of these patients with metastatic disease. The use of adjuvant therapy was a natural progression in an attempt to further improve survival. However, a number of recent publications have highlighted potential side effects associated with treatment. ${ }^{31}$ For these reasons, survivorship has become an important consideration for physicians and the focus is on 2 broad issues: late medical effects and late psychosocial effects.

\section{Late medical effects of chemotherapy}

i) Cardiovascular disease: the incidence of major cardiovascular events among 87 testicular cancer survivors who were given cisplatinbased therapy was estimated in 2000. Despite the median patient age at follow up of only 41 years, the incidence of angina with proven myocardial ischemia or myocardial infarction was $6 \%$. An important goal for future research into testicular cancer survival is the development of risk prediction models for cardiovascular disease with the subsequent construction of risk-adapted follow-up strategies and randomized intervention trials for high-risk patients. ${ }^{31}$

ii) Secondary malignant tumors: by the age of 75 years, patients who were diagnosed with seminomas or non-seminomas tumors at 35 years of age experienced cumulative risks of solid cancer of $36 \%$ and $31 \%$, respectively. ${ }^{31}$

iii) Impairment of single organ function: for example, neurotoxicity (approximately 20\% of long-term survivors of testicular cancer who were treated with cisplatin, bleomycin and vinblastine report peripheral sensory parasthesia), nephrotoxicity (most testicular cancer survivors who were treated with cisplatin-based therapy experienced an acute 
reversible decrease in glomerular filtration rate, with some sustainng irreversible damage), hypogonadism and decreased fertility (spematogenesis after treatment for testicular cancer is largely dependent on gonadal function before treatment, patient age and type of therapy) and pulmonary toxicity (risk factors for bleomycin-associated toxicity includes cumulative doses, age at diagnosis, smoking habit, renal dysfunction, mediastinal radiotherapy and oxygen administration).

\section{Late psychosocial effects}

There are a number of psychosocial issues which have been recently highlighted with chemotherapy. These include fatigue which has been reported in up to $17 \%$ of long-term testis cancer survivors. Other issues range from increased anxiety associated with fear of recurrence to alcohol abuse and a history of treatment for mental problems. The association of these issues with testis cancer survivorship and depression is less clear. All of them require a more formal assement in a clinical trial.

\section{Conclusions}

Although all three treatment options in stage I NSGCT reduce the risk of relapse and have similar outcomes, there are no randomized data demonstrating an improved outcome between one or the other. Surveillance appears particularly attractive in the low-risk setting, with two cycles of BEP chemotherapy being considered by many to be an overtreatment, as indeed International Germ Cell Cancer Collaborative Group good risk metastatic patients are treated with only three cycles of BEP. ${ }^{35}$

Due to this ongoing debate between adjuvant therapy and surveillance, decision analysis models have been investigated. ${ }^{36}$ The model incorporates cancer outcomes, treatment-related morbidity and patient preference, and then gives a quality adjusted survival prediction for each treatment option. Overall, the difference in quality-adjusted survival scores for the 3 treatment groups was low; it was also found that patients were surprisingly tolerant of treatment-related morbidity. Surveillance was in general preferred by patients if the risk of relapse was less than approximately $33 \%$, with active treatment being preferred in remaining patients with high-risk disease. The average scores for RPLND and chemotherapy varied significantly, depending on the model used. Overall, these data emphasize the attractiveness of surveillance for low-risk patients, and also underlines the difficulty in deciding between chemotherapy and RPLND as adjuvant therapy.

Today, perhaps the most important issue in stage I NSGCT is the long-term toxicity associated with treatment and surveillance. There is a desire to avoid potentially harmful chemotherapy and radiation exposure while still maximizing outcome. Surveillance guidelines are being followed. ${ }^{28}$ Ultimately, patients need to be informed of the treatment options and to be encouraged to participate in the decision making process.

\section{References}

1. Powles TB, Bhardwa J, Shamash J, et al. The changing presentation of germ cell tumours of the testis between 1983 and 2002. BJU Int 2005;95:1197-200.

2. Tandstad T, Dahl 0, Cohn-Cedermark G, et al. Risk-adapted treatment in clinical stage I non seminomatous germ cell testicular cancer: the SWENOTECA management program. J Clin Oncol 2009; 27:2122-8.

3. Albers P, Siener R, Kliesch S, et al. Risk factors for relapse in clin- ical stage I non seminomatous testicular germ cell tumors: results of the German Testicular Cancer Study Group Trial. J Clin Oncol 2003;21:1505-12.

4. Nicolai N, Miceli R, Artusi R, et al. A simple model for predicting nodal metastasis in patients with clinical stage I non seminomatous germ cell testicular tumors undergoing retroperitoneal lymph node dissection only. J Urol 2004;171:172-6.

5. Stephenson AJ, Bosl GJ, Bajorin DF, et al. Retroperitoneal lymph node dissection in patients with low stage testicular cancer with embryonal carcinoma predominance and/or lymphovascular invasion. J Urol 2005;174:557-60.

6. Stephenson AJ, Bosl GJ, Motzer RJ, et al. lymph node dissection for nonseminomatous germ cell testicular cancer: impact of patient selection factors on outcome. J Clin Oncol 2005;23:2781-8.

7. Daugaard G, Petersen PM, Rorth M. Surveillance in stage I testicular cancer. APMIS 2003;111:76-83

8. Ernst DS, Brasher P, Venner PM, et al. Compliance and outcome of patients with stage 1 non-seminomatous germ cell tumors (NSGCT) managed with surveillance programs in seven Canadian centres. Can J Urol 2005;12:2575-80.

9. Oliver RT, Ong J, Shamash J, et al; Anglian Germ Cell Cancer Group. Long-term follow-up of Anglian Germ Cell Cancer Group surveillance versus patients with Stage 1 nonseminoma treated with adjuvant chemotherapy. Urology 2004;63:556-61.

10. Sturgeon JF, Moore MJ, Kakiashvili DM, et al. Non-risk-adapted surveillance in clinical stage i nonseminomatous germ cell tumors: The Princess Margaret Hospital's Experience. Eur Urol 2011;59: 556-62.

11. Chevreau C, Mazerolles C, Soulie M, et al. Long-term efficacy of two cycles of BEP regimen in high-risk stage I non seminomatous testicular germ cell tumors with embryonal carcinoma and/or vascular invasion. Eur Urol 2004;46:209-14.

12. Dearnaley DP, Fossa SD, Kaye SB, et al. MRC Testicular Tumour Working Party. Adjuvant bleomycin, vincristine and cisplatin (BOP) for high-risk stage I non-seminomatous germ cell tumours: a prospective trial (MRC TE17).Br J Cancer 2005;92:2107-13.

13. Krege S, Beyer J, Souchon R, et al. European consensus conference on diagnosis and treatment of germ cell cancer: a report of the second meeting of the European Germ Cell Cancer Consensus group (EGCCCG): part I. Eur Urol 2008;53:478-96.

14. Reed G, Stenning SP, Cullen MH, et al. Medical Research Council prospective study of surveillance for stage I testicular teratoma: Medical Research Council Testicular Tumors Working Party. J Clin Oncol 1992;10:1762-8.

15. Cullen MH, Stenning SP, Parkinson MC, et al. Short-course adjuvant chemotherapy in high-risk stage I non seminomatous germ cell tumors of the testis: a Medical Research Council report. J Clin Oncol 1996;14:1106-13.

16. Stephenson AJ, Sheinfeld J. The role of retroperitoneal lymph node dissection in the management of testicular cancer. Urol Oncol 2004;22:225-33.

17. Sheinfeld J, Motzer RJ, Rabbani F, et al. Incidence and clinical outcome of patients with teratoma in the retroperitoneum following primary retroperitoneal lymph node dissection for clinical stages I and IIA non seminomatous germ cell tumors. J Urol 2003;170:115962.

18. Leibovitch I, Foster RS, Kopecky KK, et al. Improved accuracy of computerized tomography based clinical staging in low stage non seminomatous germ cell cancer using size criteria of retroperitoneal lymph nodes. J Urol 1995;154:1759-63.

19. Fernandez EB, Moul JW, Foley JP, et al. Retroperitoneal imaging with third and fourth generation computed axial tomography in clinical stage I nonseminomatous germ cell tumors. Urology 1994; 44:548-2. 
20. Oechsle K, Hartmann M, Brenner W, et al. [18F] Fluorodeoxyglucose positron emission tomography in non seminomatous germ cell tumors after chemotherapy: the German multicenter positron emission tomography study group. J Clin Oncol 2008;26:5930-5.

21. Freedman LS, Parkinson MC, Jones WG, et al. Histopathology in the prediction of relapse of patients with stage I testicular teratoma treated by orchidectomy alone. Lancet 1987;2:294-8.

22. Vergouwe Y, Steyerberg EW, Eijkemans MJ, et al. Predictors of occult metastasis in clinical stage I nonseminoma: a systematic review. J Clin Oncol 2003;21:4092-9.

23. Motzer RJ, Amsterdam A, Prieto V, et al. Teratoma with malignant transformation: diverse malignant histologies arising in men with germ cell tumors. J Urol 1998;159:133-8.

24. Powles TB, Bhardwa J, Shamash J, et al. The changing presentation of germ cell tumours of the testis between 1983 and 2002. BJU Int 2005;95:1197-200.

25. Subramanian VS, Nguyen CT, Stephenson AJ, Klein EA. Complications of open primary and post-chemotherapy retroperitoneal lymph node dissection for testicular cancer. Urol Oncol 2010;28:504-9.

26. Albers P, Siener R, Krege S, et al; German Testicular Cancer Study Group. Randomized phase III trial comparing retroperitoneal lymph node dissection with one course of bleomycin and etoposide plus cisplatin chemotherapy in the adjuvant treatment of clinical stage I Nonseminomatous testicular germ cell tumors: AUO trial AH 01/94 by the German Testicular Cancer Study Group. J Clin Oncol 2008;26:2966-72.

27. Stephenson AJ, Klein EA. Surgical management of low-stage non seminomatous germ cell testicular cancer.BJU Int 200;104:1362-8.

28. Cathomas R, Helbling D, Stenner F, et al. Interdisciplinary evidence-based recommendations for the follow-up of testicular cancer patients: a joint effort. Swiss Med Wkly 2010;140:356-69.
29. Huddart RA, O'Doherty MJ, Padhani A, et al. 18fluorodeoxyglucose positron emission tomography in the prediction of relapse in patients with high-risk, clinical stage I nonseminomatous germ cell tumors: preliminary report of MRC Trial TE22--the NCRI Testis Tumour Clinical Study Group. J Clin Oncol 2007;25:3090-5.

30. Stephenson AJ, Bosl GJ, Motzer RJ, et al. Nonrandomized comparison of primary chemotherapy and retroperitoneal lymph node dissection for clinical stage IIA and IIB non seminomatous germ cell testicular cancer. J Clin Oncol 2007;25:5597-602.

31. Travis LB, Beard C, Allan JM, et al. Testicular cancer survivorship: research strategies and recommendations. J Natl Cancer Inst 2010;102:1114-30.

32. Travis LB, Fossa SD, Schonfeld SJ, et al. Second cancers among 40,576 testicular cancer patients: focus on long-term survivors. J Natl Cancer Inst 2005;97:1354-65.

33. Westermann DH, Schefer H, Thalmann GN, et al. Long-term followup results of 1 cycle of adjuvant bleomycin, etoposide and cisplatin chemotherapy for high risk clinical stage I non seminomatous germ cell tumors of the testis. J Urol 2008;179:163-6.

34. Wethal T, Kjekshus J, Røislien J, et al. Treatment-related differences in cardiovascular risk factors in long-term survivors of testicular cancer. J Cancer Surviv 2007;1:8-16.

35. Rustin GJ, Mead GM, Stenning SP, et al; National Cancer Research Institute Testis Cancer Clinical Studies Group. Randomized trial of two or five computed tomography scans in the surveillance of patients with stage I nonseminomatous germ cell tumors of the testis: Medical Research Council Trial TE08, ISRCTN56475197--the National Cancer Research Institute Testis Cancer Clinical Studies Group. J Clin Oncol 2007;25:1310-5.

36. Nguyen CT, Fu AZ, Gilligan TD, et al. Defining the optimal treatment for clinical stage I non seminomatous germ cell testicular cancer using decision analysis. J Clin Oncol 2010;28:119-25. 